\title{
Conidiobolomycosis in Ovine in Southeast Bahia - Brazil
}

\author{
Gisele Dias da Silva', Fernando Alzamora Filho², Thiago Santos Ribeiro', Emilly Oliveira Santos', \\ João Luciano Andrioli ${ }^{3} \&$ Fabiana Lessa Silva ${ }^{4}$
}

\begin{abstract}
Background: Conidiobolomycosis is a highly lethal, granulomatous disease that primarily affects the respiratory system of sheep. The etiological agents are fungi of the genus Conidiobolus, including Conidiobolus coronatus, C. incongruus, and $C$. lamprageus. In Northeast Brazil, this disease is particularly important considering the significant impact sheep and goats have on the regional economy. The present report describes the occurrence of conidiobolomycosis in two sheep from the same property in the Itabuna-BA region that were referred to the Veterinary Hospital of the State University of Santa Cruz, Bahia, Brazil.

Case: The primary complaint in both animals was bilateral bloody nasal discharge over a period of approximately 15 days and frequent coughing. On physical examination, the animals exhibited "goosebumps" and opaque hair, with a body score of 1 (scale, 1-5), mild dehydration (7\%), apathy, frequent cough with putrid odor, bilateral serosanguinolent nasal discharge, craniofacial asymmetry, expiratory dyspnea, enlargement of the retropharyngeal lymph nodes, audible pulmonary rales, and pain on percussion of the pulmonary field. A therapeutic support protocol was established to stabilize the animals until the results of complete blood count, radiography, and microbiological evaluation of nasal content were available. Definitive diagnosis of disease was made by direct positive mycological examination, that revealed the presence of wide rarely septate hyphae, and isolation and cultivation of the fungus Conidiobolus sp., with microculture on slides and staining with lactophenol blue cotton. Due to disease diagnosis and the severity of injuries observed, the prognoses of both animals were considered to be unfavorable and led to euthanasia and necropsy. At necropsy, the most relevant findings were granulomatous rhinitis with ascending inflammatory processes to the meninges and adjacent structures, in addition to cranioventral areas of pulmonary consolidation with drainage of purulent exudate at the cut surface, suggestive of bronchopneumonia. Histopathology revealed intense pyogranulomatous inflammation associated with the presence of hyphae in negative images within the cytoplasm of multinucleated giant cells in the nasal cavity, lungs, meninges, and brain.

Discussion: The association of necropsy findings, histopathological changes, and microbiological isolation of the fungus facilitated understanding of the changes observed in the respiratory system and other organs, and enabled correlation between the recorded lesions and clinical manifestations exhibited by the animals. Based on the lesions observed clinically and at necropsy, both cases were diagnosed with rhinopharyngeal conidiobolomycosis. The histopathological and macroscopic changes observed were similar to what are often described in severe cases of the disease. Considering the severity of the disease and its high lethality in these animals, conidiobolomycosis can lead to significant damage of the production chain; this was observed in the present property, where three animals in a herd of 20 died with signs of the disease, highlighting the importance of the disease, particularly in the Northeast region, where the largest flocks of sheep are found in Brazil. The implementation of prophylactic measures is particularly important considering the unfavorable prognosis and the absence of effective treatments.
\end{abstract}

Keywords: Conidiobolus spp., mycosis, rhinitis, granulomatous inflammation. 


\section{INTRODUCTION}

Conidiobolomycosis is a highly lethal disease, although its incidence is considered to be low [4]. Sheep are the most frequently affected animals and exhibit the highest mortality rate $[7,15]$. The etiological agents are highly pathogenic fungi of the genus Conidiobolus, which includes the species Conidiobolus coronatus, C. Incongruus, and C. lamprageus [14]. These fungi are found more frequently in regions with tropical or subtropical climates and high humidity [2,11]. Infection can occur by inhalation of conidia present in the environment or by inoculation of microlesions in the nostrils, without horizontal transmission [1].

The frequency of conidiobolomycosis in Brazil has been reported to have increased from $0.1 \%$ in 2012 to $17.2 \%$ in 2016 , and the reported lethality is always high, often reaching 100\% [18]. In Brazil, the disease has been described in the states of Mato Grosso [4,16], Santa Catarina [6], Piauí [15], Pernambuco [8], Paraíba [12], Rio Grande do Sul [9] and Bahia [11]. In the Northeast region, this disease is particularly important considering the significant impact sheep and goats have on the regional economy.

Accordingly, the objective of the present study was to examine the clinical and pathological aspects of two cases of this disease in sheep from the southeast region of Bahia.

\section{CASE}

Two mixed-breed sheep, approximately with 3 years of age, were referred to the Large Animal Clinic of the Veterinary Hospital of the State University of Santa Cruz (HV-UESC) for medical care. The primary complaint was a 15-day history of bilateral bloody nasal discharge, in addition to frequent coughing. The animals were from the same property where, according to anamnesis, an animal had died after exhibiting the same changes. The regime adopted at the property was semi-extensive; as such, the sheep spent the days in the pasture of Brachiaria spp. and nights in the fold, where they received concentrates.

On physical examination, the animals exhibited "goosebumps" and opaque hair, with a body score of 1 (scale, 1-5), mild dehydration (7\%), apathy, frequent cough and putrid odor, bilateral serosanguinolent nasal discharge, craniofacial asymmetry, expiratory dyspnea, enlargement of retropharyngeal lymph nodes, audible pulmonary rales, and pain on percussion of the pulmonary field. In addition, one of the animals exhibited exophthalmos on its right side (Figure 1). Accordingly, conidiobolomycosis, enzootic ethmoidal tumor, rhinofacial pythiosis, and caseous lymphadenitis were suspected.

Considering the situation, the attending veterinarian recommended that the animals be hospitalized. Administration of $500 \mathrm{~mL}$ of $10 \%$ glucose solution ${ }^{1}$ and $1 \mathrm{~L}$ of Ringer's lactate ${ }^{2}$ was instituted as support therapy. In addition, ceftiofur ${ }^{3}(2 \mathrm{~mL} / \mathrm{kg})$ and flunixin meglumine ${ }^{4}(1 \mathrm{~mL})$ were prescribed. As complementary examinations, radiography of the patients' ethmoid region and chest were performed. In addition, a direct mycological examination and culture of the fungus were performed using nasal secretions. The culture procedure was made using Petri dishes containing Sabouraud $4 \%$ culture medium with incubation at $30^{\circ} \mathrm{C}$ for 5 days. After, it was performed microculture on slides and staining with lactophenol blue cotton ${ }^{5}$. Facial radiography revealed an increase in radiopacity in the periocular region and radiolucency in the sinuses, while chest radiography revealed a diffuse increase in radiopacity in the lung fields, with bronchial thickening. Two days after admission, the animals exhibited no response to the therapeutic intervention applied; as such, the clinical picture progressed, with the appearance of head oscillations in season, indicating the involvement of the central nervous system. Due to the unfavorable prognosis, the animals were euthanized

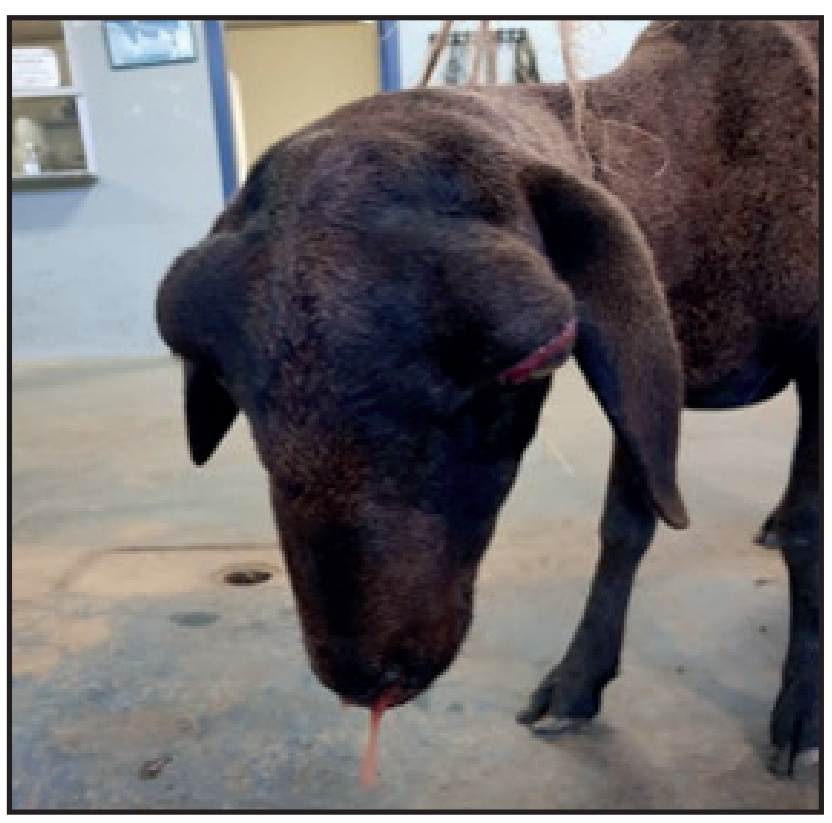

Figure 1. Sheep showing right exophthalmos and serosanguinous nasal exudate elimination. 


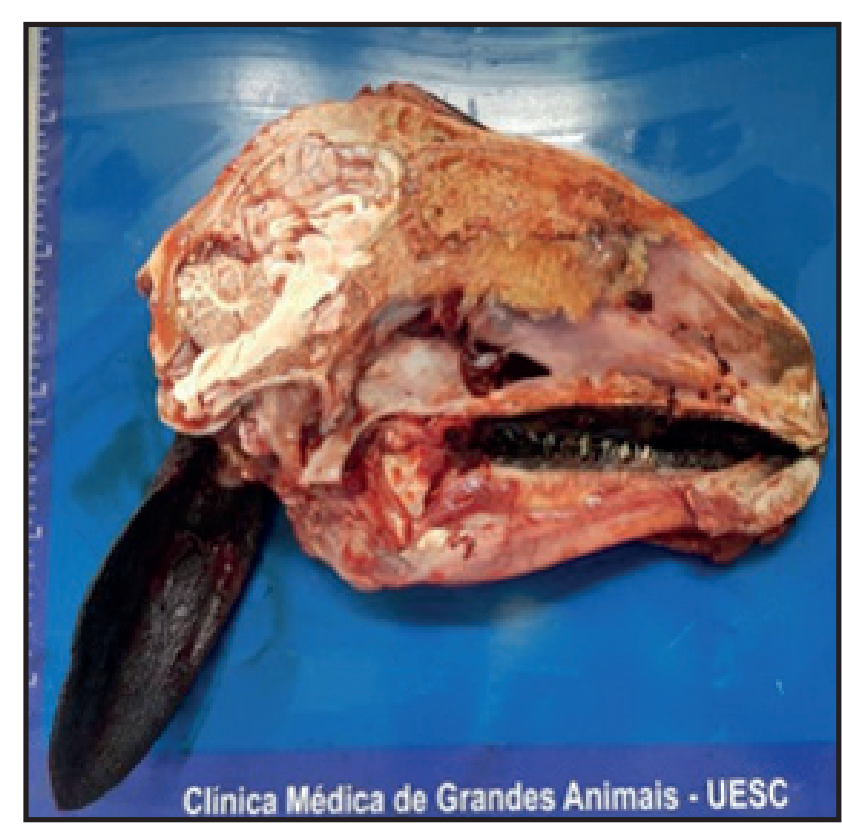

Figure 2. Skull sagittal section showing a yellowish-white irregular mass in the nasal cavity.

and sent for autopsy at the Animal Pathology service of HV-UESC.

On macroscopic examination, an intense destructive lesion was observed at the longitudinal section of the head, with the presence of an irregular mass of friable consistency and yellowish-white coloration located in the region of the ethmoid turbinates, nasal septum, and frontal sinus (Figure 2). The submandibular lymph nodes were enlarged. In the thoracic cavity of one of the sheep, consolidation of the ventral skull was observed, in addition to the presence of multiple yellowish-white nodules, measuring $0.5 \mathrm{~cm}$ to $2 \mathrm{~cm}$ in diameter, distributed throughout the lung parenchyma. Additionally, white pulp hyperplasia in the spleen and parasitic nodules with diffuse distribution in the intestinal serosa was observed in both animals. Unilateral exophthalmos was also found in one of the animals. Fragments of the nasal cavity, retropharyngeal lymph nodes, lungs, and central nervous system were collected for histopathological analysis.

Results of the microbiological analysis were available shortly after necropsy, which showed flat, glabrous and waxy colonies of cream to brown color. Microscopically, sparse hyphae and spherical propagule with papillae typical of fungi of the genus Conidiobolus were observed (Figure 3).

Histopathological analysis revealed coalescent and intense multifocal pyogranulomatous inflammation associated with the Splendore-Hoeppli reaction

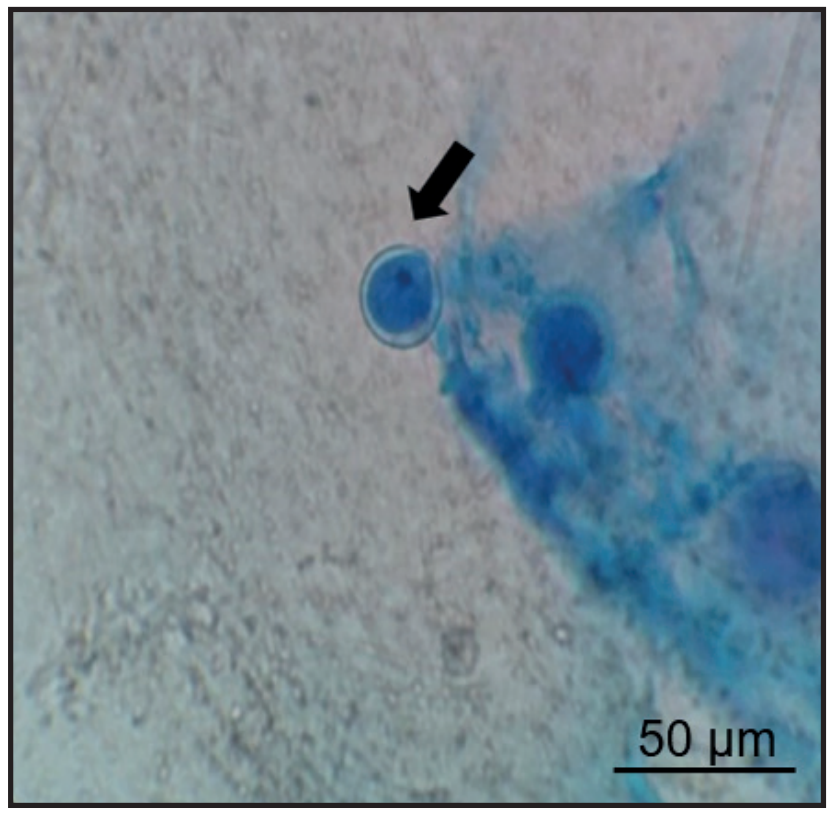

Figure 3. Conidiobolus spp. hyphae stained in blue (arrow) seen under microscopy.

(Figure 4), as well as hyphae in negative images inside multinucleated giant cells in the nasal cavity and regional lymph nodes. In one of the animals, the same pattern of injury was observed in the lungs, meninges, and brain. In addition, two special staining methods were used: the Grocott ${ }^{6}$ method, which enabled visualization of the irregular and rarely septate hyphae and with the walls staining dark grey (Figure 5); and the periodic acid-Schiff $^{7}$ (PAS) method, which highlighted the fungus body, which was intensely pink in color (Figure 6).

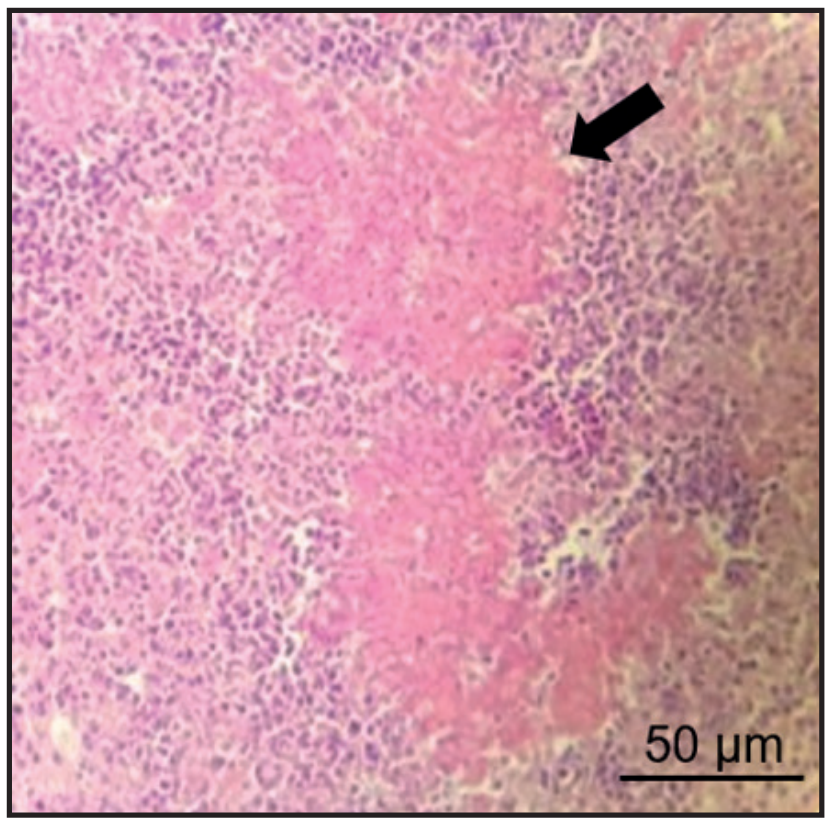

Figure 4. Intense inflammatory infiltrate organized around necrotic tissue (arrow) [H.E.; 20x]. 


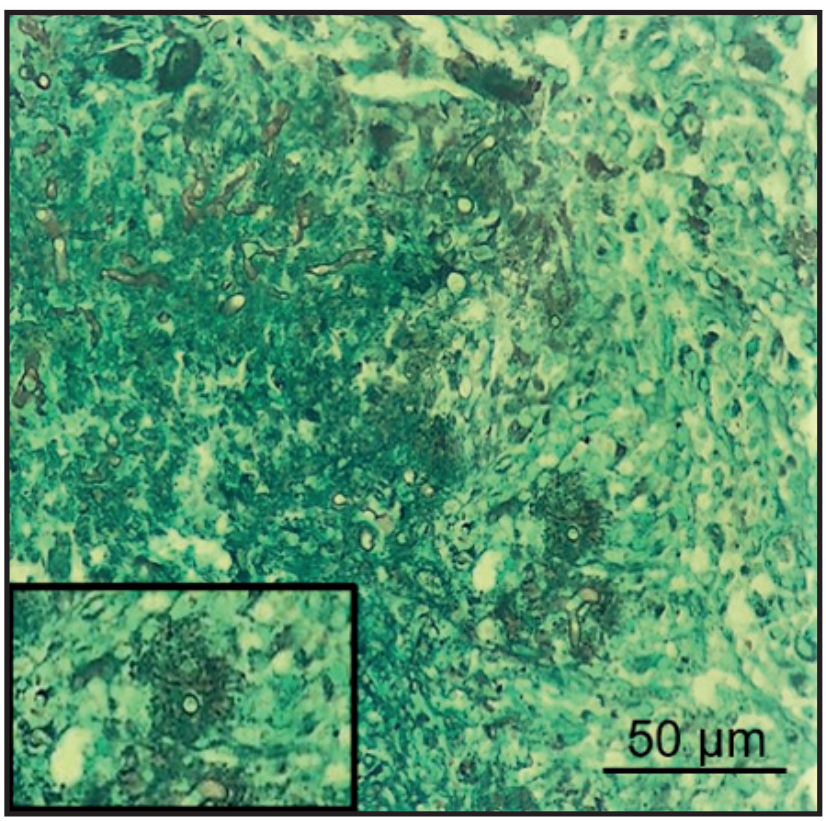

Figure 5. Fungal hyphae with blackish outlines [Grocott; 40x].

\section{DISCUSSION}

The presumptive diagnosis of conidiobolomycosis in the two sheep was established considering both clinical and pathological aspects. The mycological diagnosis, in turn, was based on microbiological culture and observation of the macroscopic and microscopic characteristics of the fungus.

Respiratory changes found through physical examination, such as the presence of bloody nasal discharge, cough, dyspnea, and exophthalmos, as well as macroscopic pathological changes observed in the nasal cavity, indicated rhinopharyngeal conidiobolomycosis. The presence of lesions in the lungs and the central nervous system, as described in this report, has also been described in the literature [10,11]. A study performed in Piauí, Brazil, reported lesions in the meninges and frontal region of the brain in $65 \%$ of the animals evaluated, with pulmonary involvement in $45 \%$ of them [15].

The presence of lesions with pathological characteristics similar to those observed in the nasal cavity was also observed in the lymph nodes, lungs, meninges, and brain of one of the animals described in this report. Such injuries have also been previously described by other authors $[4,10,15]$.

Microscopically, areas of granulomatous inflammation involving necrotic centers, hyphae surrounded by radiated eosinophilic material adjacent to the lesion compatible with Splendori-Hoeppli reaction,

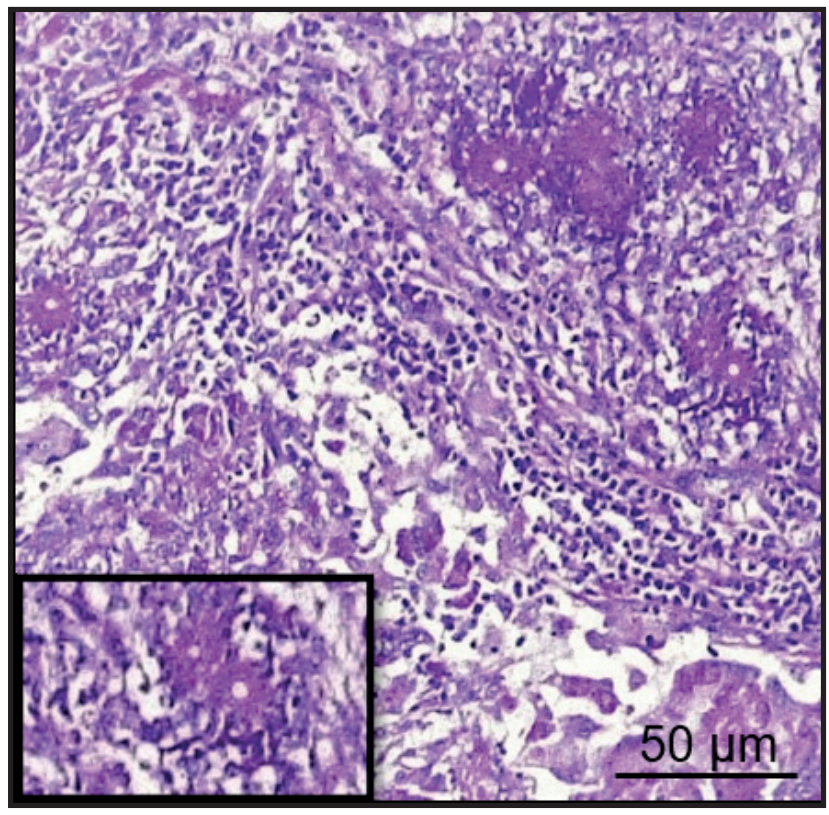

Figure 6. Necrotic areas surrounding positive PAS pink color hyphae [P.A.S; 40x].

and an intense amount of inflammatory infiltrate are also frequent in these cases [14].

Regarding conditions that may have contributed to the development of conidiobolomycosis in the animals described in this report, we highlight that they were raised in a semi-extensive system, in addition to the tropical climate and high humidity of the Ilhéus - Itabuna microregion. Furthermore, direct grazing facilitates infection due to the proximity between the nostrils and the ground, and the high humidity levels are conducive to the persistence of fungal propagules in the environment, which explains the presence of the disease on the property in question [1].

Both animals were approximately three years of age, which is consistent with what has been observed in most cases of conidiobolomycosis in sheep, where the age usually varies between three months and four years. Factors associated with disease predisposition in this age range are unknown, with the exception of a possible influence of low immunological activity at certain stages of an animal's life [3,4]. One of the animals described in this report had been lactating for three months before exhibiting initial clinical manifestations, which may have resulted in reduced immunity, taking into account the allocation of a large part of energy reserves for fetal maintenance during pregnancy and the production of postpartum milk, which renders females more susceptible to infection(s) during this period [5]. 
Regarding treatment, the application of antifungal therapy, even for prolonged periods in animals severely affected by conidiobolomycosis, does not usually yield satisfactory results. Moreover, in many situations among production animals, maintenance of this type of protocol is not considered to be economically viable [13]. For these reasons, the therapeutic management implemented in the present situation was aimed only at stabilizing the patients to perform complementary tests and confirming the diagnosis, which ultimately led to euthanasia, which was followed by necropsy.

It is important to note that there are other diseases that also affect the nasal cavity of sheep that can trigger clinical changes similar to those described here, including enzootic ethmoidal tumor, cryptococcosis, and pythiosis [17], which should also be included in the differential diagnosis. The inclusion of caseous lymphadenitis in the differential diagnosis in this case was mainly due to the high number of cases of the disease in the region studied, which can lead to a wide variety of clinical signs depending on the affected sites. The importance of histopathological evaluation, as well as microbiological analysis, is emphasized to establish a definitive diagnosis in these cases.
We conclude that conidiobolomycosis is a disease that affects several species and causes more significant changes in sheep that, in addition to being more susceptible, are raised in herds, which can lead to considerable losses in the production chain, as was observed in the present property where three animals in a herd of 20 died with signs of the disease. In view of this, the importance of the disease is highlighted, particularly in the Northeast region of Brazil, where the largest flocks of sheep are found. The implementation of prophylactic measures on properties is vital considering that the prognosis is unfavorable and there are still no effective treatments.

\section{MANUFACTURERS}

\footnotetext{
${ }^{1}$ Fresenius Medical Care. São Paulo, SP, Brazil.

${ }^{2}$ Ecoflac plus. São Gonçalo, SP, Brazil.

${ }^{3}$ Ourofino Saúde Animal. Cravinhos, SP, Brazil.

${ }^{4}$ Chemitec Produtos Veterinários. São Paulo, SP, Brazil.

${ }^{5}$ Sigma-Aldrich. Saint Louis, MO, USA.

${ }^{6}$ TECSA Laboratório. Belo Horizonte, MG, Brazil.

${ }^{7}$ CasaLab. Belo Horizonte, MG, Brazil.
}

Declaration of interest. The authors report no conflicts of interest. The authors alone are responsible for the content and writing of the paper.

\section{REFERENCES}

1 Aguiar G.M.N., Simões S.V.D., Santos S.A., Marques A.L.A., Silva T.R., Dantas A.F.M. \& Riet-Correa F. 2014. Aspectos epidemiológicos da conidiobolomicose em ovinos na região semiárida do Nordeste do Brasil. Ciência Rural. 44: 2210-2216. DOI: 10.1590/0103-8478cr20131472.

2 Almeid O.P. \& Scully C. 2002. Fungal infections of the mouth. Brazilian Journal of Oral Sciences. 1: 19-26. DOI: 10.20396/bjos.v1i1.8640965.

3 Batista M.C.S., Castro R.S., Rego E.W., Carvalho F.A.A., Silva S.M.M.S., Carvalho C.C.D. \& Riet-Correa F. 2009. Hemograma, proteinograma, ionograma e dosagens bioquímicas e enzimáticas de ovinos acometidos por conidiobolomicose no Nordeste do Brasil. Pesquisa Veterinária Brasileira. 29: 17- 24. DOI: 10.1590/S0100-736X2009000100002.

4 Boabaid F.M., Ferreira E.V., Arruda L.P., Gasparetto N.D., Souza R.L., Silva M.C., Dutra V., Nakazato L. \& Colodel E.M. 2008. Conidiobolomicose em ovinos no estado de Mato Grosso. Pesquisa Veterinária Brasileira. 28: 77-81. DOI: 10.1590/S0100-736X2008000100012

5 Castro F.A.B., Ribeiro E., Azambuja L., Mizubut I.Y., Silva L.D.F., Barbosa M.A.A.F., Marson B., Grandis F.A., Fernandes Junior F. \& Pereira E.S. 2013. Energia dietética ao final da gestação e durante a lactação e desempenho de ovinos Santa Inês em sistema de acasalamento acelerado. Semina: Ciências Agrárias. 34: 4187-4202. DOI: 10.5433/1679-0359.2013v34n6Supl2p4187.

6 Furlan F.H., Lucioli J., Veronezi L.O., Fonteque J.H., Traverso S.D., Nakazato L. \& Gava A. 2010. Conidiobolomicose causada por Conidiobolus lamprauges em ovinos no Estado de Santa Catarina. Pesquisa Brasileira Veterinária. 30: 529-532. DOI: 10.1590/S0100-736X2010000700003.

7 Martins N.S., Coelho G.B.C., Santos S., Oliveira R.A., Silva A.L.A. \& Melo F.A. 2015. Alterações da matriz extracelular esplênica em cães naturalmente infectados com Leishmania (Leishmania) infantum chagasi. Revista Brasileira de Ciência Animal. 16: 103-115. DOI: 10.1590/1089-68916i123500.

8 Mendonça F.S., Albuquerque R.F., Evêncio Neto J., Dória R.G.D., Carmargo L.M. \& Freitas S.H. 2012. Conidiobolomycosis in sheep in the state of Pernambuco. Revista Brasileira de Medicina Veterinária. 34: 241-246. 
9 Morris M, Ngeleka M., Adogwa A.O., Germain G.S. \& Higgins R. 2001. Rhinocerebral zygomycosis in a sheep. The Canadian Veterinary Journal. 42: 227-228.

10 Pedroso P.M.O., Lutier D.R., Bezerra P.S.J., Oliveira E.C., Sonne L., Dalto A.G.C. \& Driemeier D. 2009. Rinite micótica rinofaríngea em um ovino Texel no Rio Grande do Sul. Acta Scientiae Veterinariae. 37: 181-185. DOI: 10.22456/1679-9216.16248.

11 Peixoto T.C., Lima E.B., Farias S.S., Ferreira M.M., Macêdo A.G.C., Nakazato L., Pescador C.A., D’Avila M.S., Carvalho V.A.N. \& Madureira K.M. 2017. Outbreaks of conidiobolomycosis caused by Conidiobolus lamprauges in sheep in the state of Bahia, northeastern of Brazil. Brazilian Journal of Veterinary Medicine. 39: 252-263. DOI: 10.29374/2527-2179.bjvm018017.

12 Riet-Correa F., Dantas A.F.M., Azevedo E.O., Simões S.D.V., Silva S.M.S., Vilela R. \& Mendoza L. 2008. Outbreaks of rhinofacial and rhinopharyngeal zygomicosis in sheep in Paraíba, northeastern Brazil. Pesquisa Veterinária Brasileira. 28: 29-35. DOI: 10.1590/S0100-736X2008000100005.

13 Riet-Correa F., Dantas A.F.M. \& Azevedo E.O. 2011. Principais enfermidades de caprinos e ovinos no semiárido brasileiro. In: Anais do XV Congresso Latinoamericano de Buiatria da Universidade Federal de Campina Grande (Campina Grande, Brasil). p.17.

14 Silva S.M.M.S., Ferreira L.H., Souza F.A.L., Nascimento E.F., Costa E.A., Paixão T.A. \& Santos R.L. 2010. Conidiobolomicose em ovinos: reavaliação de três casos previamente diagnosticados como tumor etmoidal enzoótico. Arquivo Brasileiro de Medicina Veterinária e Zootecnia. 62: 1503-1506. DOI: 10.1590/S0102-09352010000600031.

15 Silva S.M.M.S., Castro R.S., Costa F.A.L., Vasconcelos A.C., Batista M.C.S., Riet-Correa F. \& Carvalho S.E.M. 2007. Conidiobolomycosis in sheep in Brazil. Veterinary Pathology. 44: 314-319. DOI: 10.1354/vp.44-3-314.

16 Tadano T., Paim N.P., Hueb M. \& Fontes C.J.F. 2005. Entomoftoromicose (zigomicose) causada por Conidiobolus coronatus em Mato Grosso (Brasil): relato de caso. Revista da Sociedade Brasileira de Medicina Tropical. 38: 188190. DOI: 10.1590/S0037-86822005000200013.

17 Ubiali D.G., Cruz R.A., De Paula D.A., Silva M.C., Mendonça F.S., Dutra V., Nakazato L., Colodel E.M. \& Pescador C.A. 2013. Pathology of nasal infection caused by Conidiobolus lamprauges and Pythium insidiosum in sheep. Journal of Comparative Pathology. 149: 137-145. DOI: 10.1016 / j.jcpa.2012.12.002.

18 Weiblen C., Pereira D.I.B., Dutra V., Godoy I., Nakazato L., Sangioni L.A., Santurio J.M. \& Botton S.A. 2016. Epidemiological, clinical and diagnostic aspects of sheep conidiobolomycosis in Brazil. Ciência Rural. 46: 839-846. DOI: $10.1590 / 0103-8478 \mathrm{cr} 20150935$. 